This item was submitted to Loughborough's Research Repository by the author.

Items in Figshare are protected by copyright, with all rights reserved, unless otherwise indicated.

\title{
A review of existing anatomical data capture methods to support the mass customisation of wrist splints
}

PLEASE CITE THE PUBLISHED VERSION

http://dx.doi.org/10.1080/17452759.2010.528183

PUBLISHER

(c) Taylor \& Francis

VERSION

AM (Accepted Manuscript)

LICENCE

CC BY-NC-ND 4.0

\section{REPOSITORY RECORD}

Paterson, Abby, Richard J. Bibb, and R.I. Campbell. 2019. "A Review of Existing Anatomical Data Capture Methods to Support the Mass Customisation of Wrist Splints". figshare. https://hdl.handle.net/2134/9260. 
This item was submitted to Loughborough's Institutional Repository (https://dspace.lboro.ac.uk/) by the author and is made available under the following Creative Commons Licence conditions.

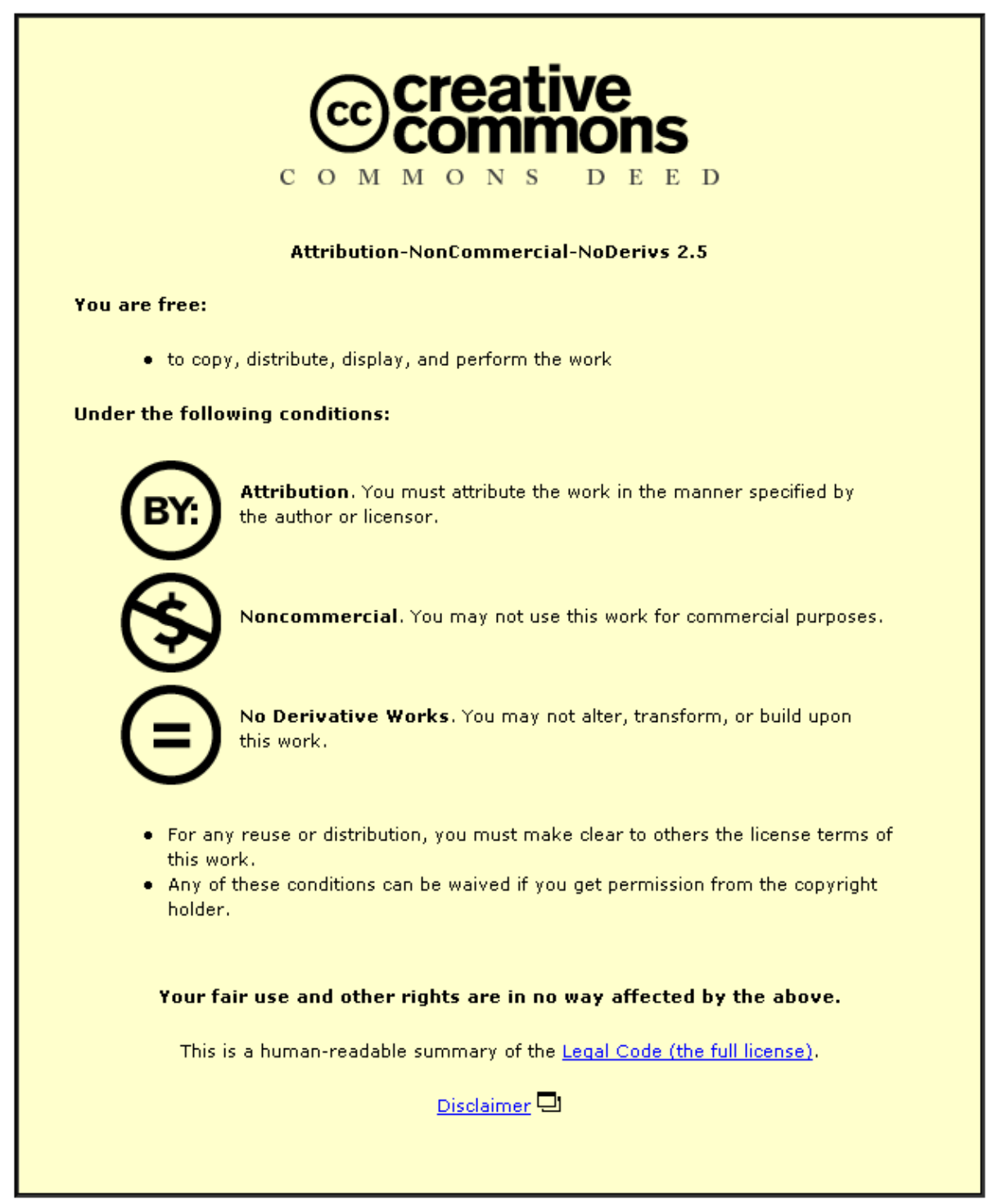

For the full text of this licence, please go to: http://creativecommons.org/licenses/by-nc-nd/2.5/ 


\title{
A review of existing anatomical data capture methods to support the mass customisation of wrist splints
}

\author{
Abby Megan Jayne Paterson (corresponding author) - PhD student \\ Preferred appearance on manuscript; A.M.J. Paterson \\ Email: a.m.paterson@lboro.ac.uk \\ Tel: 01509222783 \\ Loughborough Design School, Loughborough University, Loughborough, UK
}

Dr. Richard J. Bibb - Senior lecturer

Preferred appearance on manuscript; R.J. Bibb

Email: r.j.bibb@lboro.ac.uk

Tel: 01509228333

Loughborough Design School, Loughborough University, Loughborough, UK

Dr. Robert Ian Campbell - Reader in Computer Aided Product Design

Preferred appearance on manuscript; R.I. Campbell

Email: r.i.campbell@lboro.ac.uk

Tel: 01509228312

Loughborough Design School, Loughborough University, Loughborough, UK

All correspondence to Abby Paterson.

Full postal details: Bridgeman Centre, Loughborough University, Loughborough, Leicestershire, LE11 3TU, United Kingdom 


\title{
A review of existing anatomical data capture methods to support the mass customisation of wrist splints
}

\begin{abstract}
Anatomical data acquisition methods used within medicine exhibit various strengths and weaknesses, particularly with regards to accuracy, resolution, patient comfort and safety. Difficulties with data acquisition of wrist and hand geometry are often underestimated, and a suitable method is yet to be identified and standardised to capture skin surface topography to support the mass customisation of wrist splints. The aim of this investigation is to identify a suitable data acquisition method, capable of digitising collected data of the wrist and hand, for manipulation and conversion into a suitable file format to create customised wrist splints using additive manufacture. Literature suggests that scanning inanimate objects such as plaster casts using multiple three-dimensional laser scanners can provide adequate quality scans with suitable accuracy and resolution, with low cost and low risk to the patient. However, post processing would be required to create a "watertight" digital model suitable for additive manufacture.
\end{abstract}

Keywords: Additive manufacture, mass customisation, data acquisition, splints, orthotics

\section{Introduction}

Mass customisation (MC) is an increasingly common and popular manufacturing approach in many disciplines, particularly when combined with additive manufacture (AM). The MC-AM relationship is expanding and progressing, from the consumer market through to the medical industry for development of surgical planning, teaching, preparation aids and assistive technologies (Webb 2000). MC is intended to collect the needs and requirements of the enduser to make their life easier and more comfortable through customised fit, function, performance and aesthetics; the European Initiative project CUSTOM-FIT illustrates the need for customisation, with particular interest in assistive technologies for disabled users (Gerrits et al. 2004). Therefore, anatomical data capture is essential for the manufacture of customised assistive devices.

According to E. Donnison (personal communication, 4 February 2010), the prescription of wrist splints inevitably requires a certain amount of customisation to suit the patient's individual fit and requirements, regardless of whether the splints are fully custom-fitted or pre-fabricated 'off the shelf' splints. This is particularly relevant for patients with degenerative diseases such as rheumatoid arthritis, as patients often need splints that will be comfortable, robust and long-lasting. A wide range of literature suggests the suitability of anatomical imaging equipment such as Magnetic Resonance Imaging (MRI) and Computed Tomography (CT) for the design of prosthetics and orthotics, but very little research has been focused into the data acquisition of hand and wrist geometry for the mass customisation of wrist splints (Minns et al. 2003, Bibb 2006, Bibb and Winder 2010).

A US patent application by Fried (2007) stated ownership of a process for creating wrist splints, from data acquisition of anatomical features of wrists and hands, through to splint fabrication using AM. However, data acquisition of the wrists and hands is not a straightforward process. As of yet, there is no standardised method for collecting topographical skin surface data for the wrists and hands, and numerous problems emerge with various data collection methods. Therefore, this paper evaluates the strengths and weaknesses of four different data acquisition methods; CT, MRI, 3D laser scanning and anthropometrics. The most suitable method will be identified to support the digitisation process of customised wrist splint design and manufacture for small-scale research. It should be noted that this 
report is not a comprehensive study into all data acquisition methods, nor does it imply that the chosen method is suitable for any or all clinical applications, but reviews the most common data acquisition types discussed in other case studies within the field of medicine to support ongoing research.

\section{Data acquisition methods}

\subsection{Non-contact data acquisition}

\subsubsection{Computed Tomography}

CT is widely used within medicine, typically for diagnostics and surgical planning. CT has the ability to generate both $3 \mathrm{D}$ and $4 \mathrm{D}$ images, along with quality volume-rendered imaging. The patient is placed between an $\mathrm{x}$-ray tube and a detector array; $\mathrm{x}$-rays pass through the patient, and the level of attenuation is detected by the detector array, then logged by a computer (Goodenough 2000). Measurements are taken from various angles to produce a series of axial slices, and are illustrated in grey scale to demonstrate different densities within the body, ranging from black to represent air, and white to represent the densest bone (Bibb 2006). There are now two main types of CT; sequential and spiral (Goodenough 2000). Spiral CT can capture data in real time to produce high quality 4D imagery, and can be used for functional analysis procedures such as CT-coronary angiography and diagnosis of joint instability (Feyter et al. 2007, Tay et al. 2007). This is particularly beneficial for patients who are unable to maintain a still position (Bibb 2006, Feyter et al. 2007). Other advantages of CT are high image resolution between soft tissue, bone and air, and the ability to improve contrast and decrease structure noise. Users can also focus on a specified field of view to produce more accurate scans (Bibb 2006, Goodenough 2000). For these reasons, CT within anaplastology for the design of prosthetics is now standard practise, and is often linked with additive manufacture for prosthetic fabrication (Bibb 2006, Eggbeer 2008).

However, there are several drawbacks to CT imaging. Radiation is the biggest concern; CT imaging was dismissed by Chua et al. (2000) for prosthetic design due to radiation exposure. Radiation exposure is directly proportional to the duration of scanning, so higher image resolution and larger area coverage will require longer scanning times, thus exposing patients to greater radiation dosage (Bibb and Winder 2010, Tay et al. 2007). Bibb and Winder (2010) state that radiologists should rationalise the acceptable level of accuracy and resolution from CT imaging, so scanning times may be balanced with radiation exposure. Also, resolution between different soft tissues is often poor because collected images are divided by pixel shade; two different densities that 'share' a pixel create an intermediate density, known as the 'partial pixel effect' which can create a blurred boundary (Bibb 2006). Minns et al. (2003) identified issues in lack of definition when combining CT imagery with AM; CT slice distances can range from $0.5 \mathrm{~mm}$ upwards, whereas certain AM equipment can be capable of creating $0.15 \mathrm{~mm}$ thick layers (Bibb 2006). Therefore, intermediate sections between CT data layers are required. Also, a large field of view can demonstrate poor resolution when scanning small, intricate detailing (Bibb et al. 2010). However, Tay et al. (2007) justify the use of CT for wrist function analysis, since they claim that the wrist is not sensitive to radiation. 


\subsubsection{Magnetic resonance imaging}

Approximately 500 MRI machines are in use within the UK, and over 20,000 worldwide (Winters 2008). MRI uses three different magnetic fields; a static magnetic field, a switched gradient field and a pulsed radio frequency field. The combination of these fields causes hydrogen atoms within the body to align, so the equipment can differentiate between reactions and physical attributes (Bibb and Winder 2010, Winters 2008, Pickens 2000). MRI image 'slices' can be used solely for diagnoses, or combined through suitable medical software into a 3D virtual form for design and fabrication of surgical guides and prosthetics (Bibb 2006, Fitzpatrick et al. 1998). The captured data illustrates different densities; areas with a high concentration of hydrogen atoms, such as soft tissue, are represented in light grey scales, whereas areas with low hydrogen atom concentration appear darker (Bibb 2006). Therefore, MRI is excellent at differentiating between different soft tissues and air in close proximity, and can be used for capturing skin surfaces (Bibb 2006).

Various strengths are associated with MRI such as high resolution of soft tissue and bone morphology, and unlike CT, patients are not exposed to radiation (NHS 2009). However, there are several disadvantages. Over one million examinations are performed using MRI equipment in the UK each year. Therefore, the equipment is in high demand amongst a wide variety of medical specialities, and waiting times can be lengthy (NHS 2009). This is particularly relevant when considering patients who require more urgent access to MRI equipment. The mechanical design of the equipment can also deter patients suffering from claustrophobia, and the noise created may be unnerving (Bibb 2006, Laurence 2000, Wiklund and Wilcox 2005). MRI scanning can also be time consuming, and movement can cause distortion and shadowing. Various studies have investigated the administration of general anaesthesia and patient sedation during MRI screening to gather 'undisturbed' data imagery, but these methods may come with concerns, particularly for children and individuals with compromised health conditions (Laurence 2000, Low et al. 2008, Lawson 2000). Patients with pace makers, cardioverter-defibrillators and metal fabricated implants also face difficulties, as exposure to strong magnetic fields could be detrimental to patient health, although Roguin (2009) discusses these concerns and rationalises MRI usage after careful clinical evaluation.

To date, no literature has been found with regards to collecting skin surface topography of the wrist and hand using MRI. This may be because volume rendered imaging is rarely performed on MRI scanning due to the time involved in scanning and processing data, and most diagnoses can be performed with single accurate slice images.

\subsubsection{D laser scanning}

3D laser scanning is becoming more prominent within medicine; Chua et al. (2000) chose this method over other 'conventional' methods for prosthesis modelling, such as Plaster-of-Paris impressions, MRI and CT. Laser scanning has also been used to assess anatomical changes in facial morphology over time to demonstrate its suitability (Kau et al. 2005). A significant benefit is that only the patient's skin surface is captured, as shown in Figure 1(a). This substantially reduces data file sizes compared to MRI and CT imagery which also capture imaging of internal anatomy (Chua et al. 2000). Processing time is also significantly reduced; point cloud data can be converted to a polygonal mesh within 3D CAD based software. Another benefit is the speed of data collection. Kau et al. (2005) reported facial scanning 
times of 2.5 seconds, and depending on the optical equipment used, accuracy can be as high as $0.05 \mathrm{~mm}$ (Bibb et al. 2000). The financial benefits of 3D laser scanning are also an incentive when compared to CT and MRI, offering affordable hardware, software and minimal training requirements, which correspond to ease of use, availability, accessibility, efficiency, validity and repeatability (Kau et al. 2005).

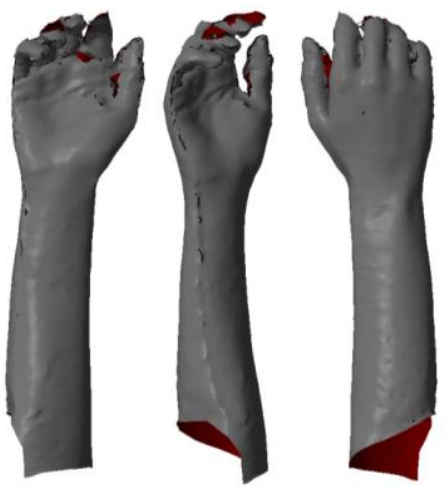

Figure 1(a): Polygonal mesh from direct 3D laser scanning

However, one significant problem is the inability to capture wanted internal structures and intricate surfaces due to line-of-sight limitations (Bibb et al. 2000, Surendran et al. 2009). This is particularly relevant to the application of prosthetics and orthotics. Certain topographic sections of the human anatomy have intricate creases and folds, particularly between fingers and the thenar webbing when the hand is in a neutral position; scanning these areas can result in void data and unwanted point convergence, as demonstrated in Figure 1(b) (Chua et al. 2000, Bibb et al. 2010, Li et al. 2008a). Various sources suggest using reverse engineering software capable of post processing to produce a 'watertight' model by repairing and re-sculpturing void data (Chua et al. 2000, Bibb et al. 2000, Surendran et al. 2009). However, this process can be time consuming, and may not be a true representation of the scanned object once corrected (Bibb et al. 2000). Bibb et al. (2000) suggested another approach to capture shadowed data by collecting and combining several overlapping scan data files to produce a complete model. However, data point density would increase, and alignment of point clouds may be difficult (Bibb et al. 2000, Surendran et al. 2009). Another limitation to 3D laser scanning is inaccurate data acquisition due to involuntary movement, causing noise and distortion (Bibb 2006), and this concern is particularly relevant to this investigation. Two studies have suggested using custom-made position jigs to prevent movement and to achieve better scanning results with limited success (Bibb et al. 2000, Li et al. 2008a). 

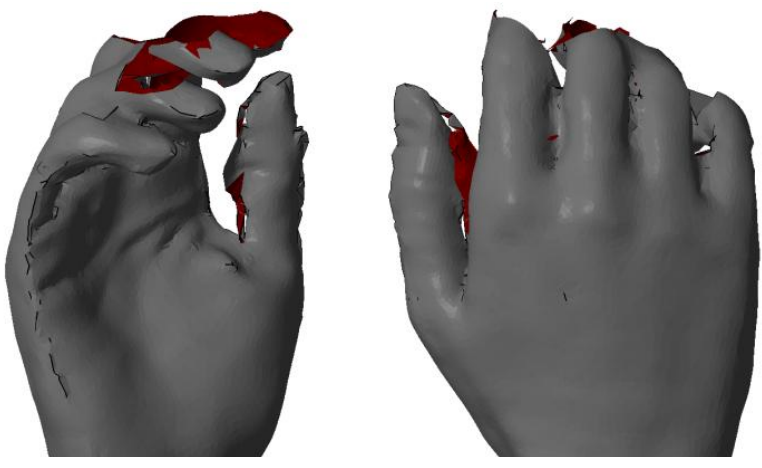

Figure 1(b): Polygonal mesh from direct 3D laser scanning. Ambiguous data has been caused by involuntary movement of the fingers during scanning. Data voids and unwanted point convergence are apparent in the extremities, as illustrated by the inconsistent surfaces.

In contrast, Direct Dimensions (2010) identified an accurate technique of capturing anatomical attributes to support the fabrication of a lifelike prosthetic hand using AM (Figure 2). The process involved scanning a plaster cast model of a patient's hand in a neutral position (Direct Dimensions 2010). Two laser scanners were mounted to a Faro Arm and a motorised precision coordinate measuring machine. The setup was capable of capturing intricate detail such as pores and creases (Direct Dimensions 2010). The case study demonstrates that scanning can be effective when scanning inanimate objects, because concerns over involuntary movement are diminished. This method is supported by Tikuisis et al. (2001), who reported highly accurate resolution of scanned hand data. Based on the conclusion of Surendran et al. (2009), Plaster of Paris would be a very effective material for scanning, due to its matte appearance, even colour tone, opacity and its ability to capture fine detail, but casting can be messy, time consuming and may be uncomfortable for patients.

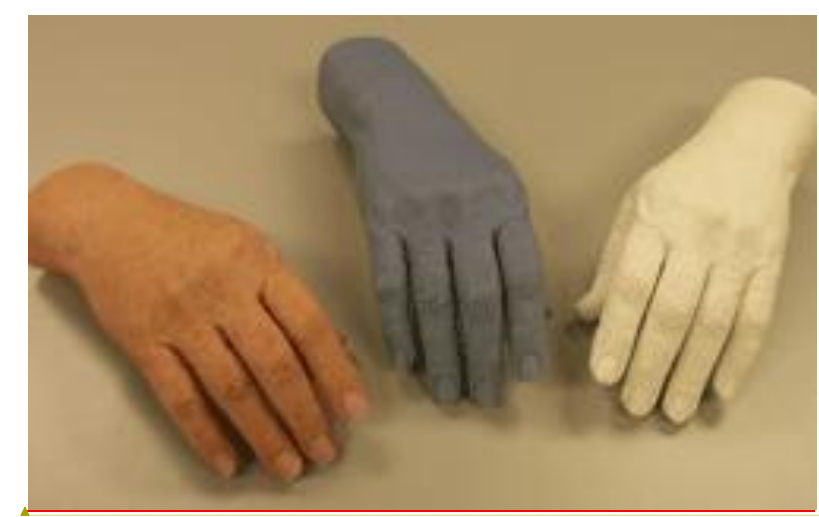

Formatted: Font: Times New Roman, $12 \mathrm{pt}$, Not Bold, Font color: Red

Figure 2: Prosthetic hand production. 3D scan data was captured by scanning a plaster cast (right), and was used to produce a realistic artificial hand fabricated by additive manufacture (left). Image courtesy of Direct Dimensions (2010) 


\subsection{Contact data acquisition}

\subsubsection{Anthropometrics}

A report by Greiner (1990) has been stated as a reliable resource for accurate anthropometric measurement techniques for hands (Wilcox 2005). Callipers and goniometers are often used within orthopaedics for measurement and assessment of joint range of movement (Gajdosik and Bohannon 1987). Williams (2007) designed a technique for creating customised gloves by collecting key anthropometric measurements using callipers and goniometers. The values were entered into a parameter table, and the parametric 3D CAD hand model updated to meet these dimensions (Figure 3). The parametric model was then converted into a suitable format for AM. Li et al. (2008b) investigated the concept of extracting anthropometric data from scanned resin hand casts, stating that this would be a successful approach in future anthropometrics.

However, collecting enough anthropometric data to construct a wrist splint would be costly in time and labour, and would potentially demonstrate high error if measurements were entered incorrectly into a parametric model within a 3D CAD program. Particular difficulties would come from measuring prominent bony landmarks and contours within the wrist such as the radial styloid process, ulnar styloid process and pisiform (Li et al. 2008a, Srinivas Reddy and Compson 2005). Since the hand and wrist have many degrees of freedom, any movement within the joints could affect the measurements, which in turn could invalidate other dependent measurements.
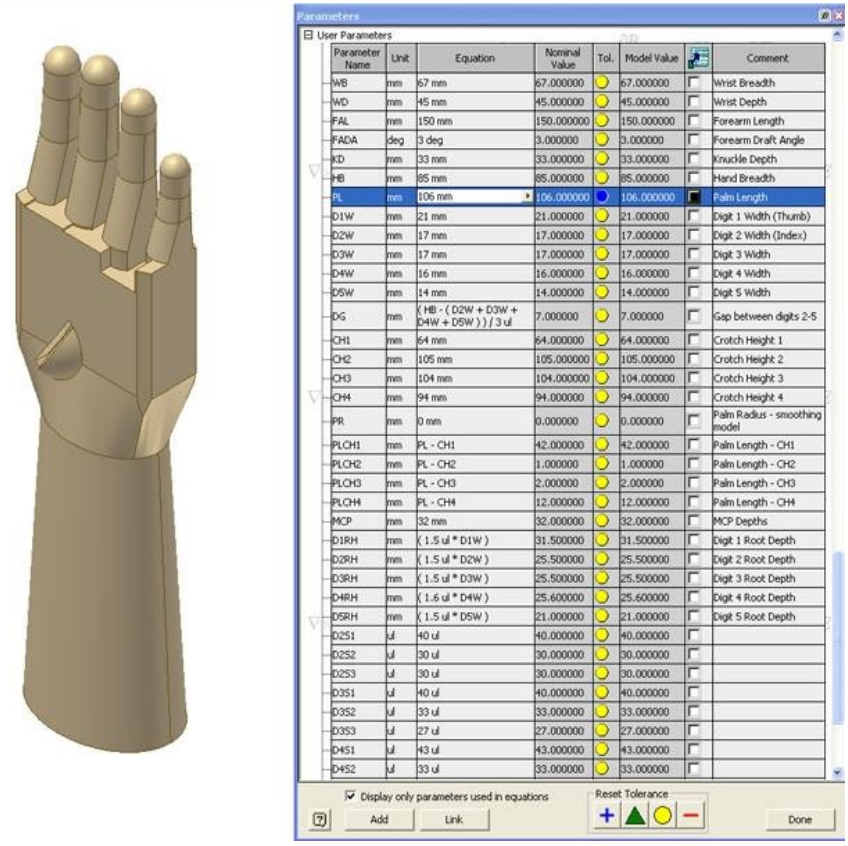

Figure 3: Parametric 3D hand model based on anthropometric measurements for customised glove design. Image courtesy of Williams (2007) 


\section{Conclusion and future work}

This review has illustrated that there is no standardised method to capture the entire surrounding skin surface topography of the wrist and hand to support customised splint design and manufacture. Table 1 lists the ideal characteristics for data acquisition methods targeted at splint design.

\begin{tabular}{|c|c|c|c|c|c|}
\hline Data capture & CT/MRI & Anthropometry & $\begin{array}{l}\text { Direct 3D } \\
\text { laser } \\
\text { scanning }\end{array}$ & $\begin{array}{l}\text { Indirect 3D } \\
\text { laser scanning } \\
\text { (support jig) }\end{array}$ & $\begin{array}{c}\text { Indirect 3D laser } \\
\text { scanning } \\
\text { (plaster cast) }\end{array}$ \\
\hline $\begin{array}{l}\text { No trained } \\
\text { specialists required }\end{array}$ & $\mathrm{X}$ & $\checkmark$ & $\checkmark$ & $\checkmark$ & $\checkmark$ \\
\hline $\begin{array}{l}\text { Affordable for low } \\
\text { budget projects }\end{array}$ & $\mathrm{X}$ & $\checkmark$ & $\checkmark$ & $\checkmark$ & $\checkmark$ \\
\hline Quick, easy access & $\mathrm{x}$ & $\checkmark$ & $\checkmark$ & $\checkmark$ & $\checkmark$ \\
\hline $\begin{array}{l}\text { Low/no waiting } \\
\text { times }\end{array}$ & $\mathrm{X}$ & $\checkmark$ & $\checkmark$ & $\checkmark$ & $\checkmark$ \\
\hline $\begin{array}{l}\text { Minimum } \\
\text { preparation time }\end{array}$ & $\checkmark$ & $\checkmark$ & $\checkmark$ & $\mathrm{X}$ & $\checkmark$ \\
\hline $\begin{array}{l}\text { Quick data } \\
\text { collection }\end{array}$ & $\begin{aligned} \mathrm{MRI} & =\mathrm{X} \\
\mathrm{CT} & =\sqrt{ }\end{aligned}$ & $\mathrm{X}$ & $\checkmark$ & $\checkmark$ & $\checkmark$ \\
\hline $\begin{array}{l}\text { Low/no discomfort } \\
\text { for patients }\end{array}$ & $\checkmark$ & $\checkmark$ & $\checkmark$ & $\checkmark$ & $\checkmark$ \\
\hline $\begin{array}{l}\text { No health/safety } \\
\text { risks to patients }\end{array}$ & $\mathrm{X}$ & $\checkmark$ & $\checkmark$ & $\checkmark$ & $\checkmark$ \\
\hline $\begin{array}{l}\text { Low risk of data } \\
\text { capture error }\end{array}$ & $\checkmark$ & $\mathrm{X}$ & $\mathrm{X}$ & $\begin{array}{l}\text { Dependant on the } \\
\text { suitability of the jig }\end{array}$ & $\checkmark$ \\
\hline Suitable accuracy & $\checkmark$ & $\checkmark$ & $\checkmark$ & $\checkmark$ & $\checkmark$ \\
\hline Suitable resolution & $\checkmark$ & $\checkmark$ & $\checkmark$ & $\checkmark$ & $\checkmark$ \\
\hline $\begin{array}{l}\text { Data capture } \\
\text { unaffected by } \\
\text { movement }\end{array}$ & $\begin{aligned} \text { MRI } & =X \\
C T & =\sqrt{ }\end{aligned}$ & $\mathrm{X}$ & $\mathrm{X}$ & $\begin{array}{l}\text { Dependant on the } \\
\text { suitability of the jig }\end{array}$ & $\checkmark$ \\
\hline $\begin{array}{l}\text { No line-of-sight } \\
\text { limitations }\end{array}$ & $\checkmark$ & $\checkmark$ & $\mathrm{X}$ & $\mathrm{X}$ & $\mathrm{X}$ \\
\hline $\begin{array}{l}\text { Little/no concern } \\
\text { over positioning }\end{array}$ & $\checkmark$ & $\mathrm{X}$ & $\mathrm{X}$ & $\mathrm{x}$ & $\checkmark$ \\
\hline $\begin{array}{l}\text { Reliable } \\
\text { repeatability }\end{array}$ & $\checkmark$ & $\mathrm{X}$ & $\mathrm{X}$ & $\begin{array}{l}\text { Dependant on the } \\
\text { suitability of the jig }\end{array}$ & $\checkmark$ \\
\hline $\begin{array}{l}\text { Direct export into } \\
\text { 3D CAD software }\end{array}$ & $\checkmark$ & $\mathrm{X}$ & $\checkmark$ & $\checkmark$ & $\checkmark$ \\
\hline
\end{tabular}

Table 1: Comparison of different data capture methods and ideal characteristics $\checkmark=$ True $X=$ False 
A common problem amongst all data acquisition methods is voluntary and involuntary movement, and this may be particularly problematic for patients who suffer from medical conditions such as Parkinson's disease. Therefore, methods of immobilisation through jigging or casting may be the most effective method to support data collection. However, given the range of movement capable from the joints within the wrists and hands, jigging may not be the most appropriate method, as the jig itself would need to cover joints and may interfere with data collection, particularly with 3D laser scanning. Jigging would be most appropriate for capturing anatomical contouring of the wrist and forearm, but if the patient requires additional support around the fingers, i.e. to prevent ulnar drift, then a polygonal mesh between the fingers may be necessary to create this additional support; this may be difficult and time consuming to capture.

Findings conclude that in terms of accuracy, resolution, patient safety, cost, speed and efficiency, laser scanning appears to be the most suitable to meet all needs, particularly when combined with plaster casting to reduce collection of ambiguous data. From an orthopaedic aspect (E. Donnison, personal communication, 4 February 2010), it is important to note that hands should be cast in the neutral or intrinsic plus position if possible, or a rested comfortable position if the splint is for a patient with a degenerative disease such as rheumatoid arthritis. It is an accepted fact that collecting scanned data between fingers is difficult, particularly when the hand is in a neutral position. Therefore, plaster casts could be placed and scanned in several different orientations if using fixed position laser scanners, until acceptable data is collected between the fingers. Hand-held laser scanners will also allow free movement around the plaster cast to capture greater detail of intricate surfaces from different angles. This will form the focus for future research, since a cast can provide and maintain a constant reference position suitable for repeatability testing.

Also, by using the technique suggested by $\mathrm{Li}$ et al. (2008b), anthropometric measurements could also be taken from a plaster cast if required, without further consultation with the patient. Although the casting process can be time consuming and messy, physical and digital versions of the patient's hand could be kept on record, which may be useful for orthopaedics when assessing disease progression. The process may be similar to the case study by Kau et al. (2005) with regards to changes of facial structure captured using laser scanning. How accurate the scan data would need to be to fabricate a comfortable form around the patient's wrist and hand is yet to be established. However, it is assumed that point density should vary throughout the model, with a denser point count around complex geometry, and a sparse point count to represent simpler geometry. Reverse engineering software capable of point cloud manipulation could be used to tailor scan data to a suitable level of accuracy in order to reduce file sizes and processing time. It may also be unnecessary to capture anatomical data between the fingers, but consultation with orthopaedics may demonstrate different requirements for each individual patient depending on the severity of the condition and their individual needs with regards to levels of wrist and hand immobilisation.

\section{Acknowledgements}

Many thanks to Loughborough University for funding the research described. Figure 2 has been reproduced with the permission of Michael Raphael at Direct Dimensions, Inc. Figure 3 was kindly provided with the permission of Gavin Williams at Loughborough University. Special thanks to Ella Donnison and Lucia Ramsey for their help, advice and contribution. 


\section{References}

Bibb, R., 2006. Medical Modelling: The Application of Advanced Design and Development Techniques in Medicine. Cambridge: Woodhead Publishing.

Bibb, R., Eggbeer, D. and Evans, P., 2010. Rapid Prototyping technologies in soft tissue facial prosthetics: current state of the art. Rapid Prototyping Journal, 16 (2), 130-137.

Bibb, R., Freeman, P., Brown, R., Sugar, A., Evans, P. and Bocca, A., 2000. An investigation of three-dimensional scanning of human body surfaces and its use in the design and manufacture of prostheses. Proceedings of the Institution of Mechanical Engineers. Part H, Journal of engineering in medicine, 214 (6), 589-594.

Bibb, R. and Winder, J., 2010. A review of the issues surrounding three-dimensional computed tomography for medical modelling using rapid prototyping techniques. Radiography, 16 (1), 78-83.

Chua, C.K., Chou, S.M., Lin, S.C., Lee, S.T. and Saw, C.A., 2000. Facial prosthetic model fabrication using rapid prototyping tools. Integrated Manufacturing Systems, 11 (1), 42-53.

Direct Dimensions, 2010. Case Study: Using 3D Imaging to Create High-Res Prosthetic Hand [Online], Direct Dimensions, Inc. Available from: http://directdimensions.blogspot.com/2010/01/case-study-using-3d-imaging-to-create.html [Accessed 22 February, 2010].

Eggbeer, D., 2008. The Computer Aided Design and Fabrication of Facial Prostheses. Thesis (PhD). University of Wales.

Feyter, P.J.D., Meijboom, W.B., Weustink, A., Van Mieghem, C., Mollet, N.R.A., Vourvouri, E., Nieman, K. and Cademartiri, F., 2007. Spiral Multislice Computed Tomography Coronary Angiography: A Current Status Report. Clinical cardiology, 30 (9), 437-442.

Fitzpatrick, J.M., Hill, D.L., Shyr, Y., West, J., Studholme, C. and Maurer, C.R. Jr., 1998. Visual assessment of the accuracy of retrospective registration of MR and CT images of the brain. IEEE Transactions on Medical Imaging, 17 (4), 571-585.

Fried, S., 2007. Splint and or Method of Making Same. United States Patent Application 2007/0016323, January 18.

Gajdosik, R.L. and Bohannon, R.W., 1987. Clinical Measurement of Range of Motion: Review of Goniometry Emphasizing Reliability and Validity. Physical Therapy, 67 (12), 1867-1872.

Gerrits, A., Jones, C.L. and Valero, R., 2004. Custom-fit: a knowledge-based manufacturing system enabling the creation of custom-fit products to improve the quality of life, Rapid Product Development Conference, October 12-13 2004, Marinha Grande, Portugal.

Goodenough, D.J., 2000. Tomographic Imaging. In: J. Beutel, H.L. Kundel and R.L. Van Metter, eds, Handbook of Medical Imaging, Volume 1. Physics and Psychophysics.

Bellingham, Washington: The International Society for Optical Engineering, 511-554. 
Greiner, T., 1990. Hand Anthropometry of U.S. Military Personnel. Washington D.C.: United States Department of Defense.

Kau, C.H., Zhurov, A., Bibb, R., Hunter, L. and Richmond, S., 2005. The investigation of the changing facial appearance of identical twins employing a three-dimensional laser imaging system. Orthodontics \& craniofacial research, 8 (2), 85-90.

Laurence, A.S., 2000. Sedation, safety and MRI. The British journal of radiology, 73 (870), 575-577.

Lawson, G.R., 2000. Sedation of children for magnetic resonance imaging. Archives of Disease in Childhood, 82 (2), 150-153.

Li, Z., Chang, C., Dempsey, P.G. and Cai, X., 2008a. Refraction effect analysis of using a hand-held laser scanner with glass support for 3D anthropometric measurement of the hand: A theoretical study. Measurement, 41 (8), 842-850.

Li, Z., Chang, C.C., Dempsey, P.G., Ouyang, L. and Duan, J., 2008b. Validation of a threedimensional hand scanning and dimension extraction method with dimension data. Ergonomics, 51 (11), 1672-1692.

Low, E., O'Driscoll, M., MacEneaney, P. and O'Mahony, O., 2008. Sedation with oral chloral hydrate in children undergoing MRI scanning. Irish medical journal, 101 (3), 80-82.

Minns, R.J., Bibb, R., Banks, R. and Sutton, R.A., 2003. The use of a reconstructed threedimensional solid model from CT to aid the surgical management of a total knee arthroplasty: a case study. Medical engineering \& physics, 25 (6), 523-526.

NHS, 2009. MRI-scan - Advantages and disadvantages [Online], National Health Service. Available from: http://www.nhs.uk/Conditions/MRI-scan/Pages/Advantages.aspx [Accessed 2 February, 2010].

Pickens, D., 2000. Magnetic Resonance Imaging. In: J. Beutel, H.L. Kundel and R.L. Van Metter, eds, Handbook of Medical Imaging, Volume 1. Physics and Psychophysics. Bellingham, Washington: The International Society for Optical Engineering, 373-461.

Roguin, A., 2009. Magnetic Resonance Imaging in Patients With Implantable CardioverterDefibrillators and Pacemakers. Journal of the American College of Cardiology, 54 (6), 556557.

Srinivas Reddy, R. and Compson, J., 2005. (i) Examination of the wrist-surface anatomy of the carpal bones. Current Orthopaedics, 19 (3), 171-179.

Surendran, N.K., Xu, X.W., Stead, O. and Silyn-Roberts, H., 2009. Contemporary technologies for 3D digitization of Maori and Pacific Island artifacts. International Journal of Imaging Systems and Technology, 19 (3), 244-259.

Tay, S.C., Primak, A.N., Fletcher, J.G., Schmidt, B., Amrami, K.K., Berger, R.A. and McCollough, C.H., 2007. Four-dimensional computed tomographic imaging in the wrist: proof of feasibility in a cadaveric model. Skeletal radiology, 36 (12), 1163-1169. 
Tikuisis, P., Meunier, P. and Jubenville, C., 2001. Human body surface area: measurement and prediction using three dimensional body scans. European journal of applied physiology, 85 (3), 264-271.

Webb, P.A., 2000. A review of rapid prototyping (RP) techniques in the medical and biomedical sector. Journal of Medical Engineering \& Technology, 24 (4), 149-153.

Wiklund, M.E. and Wilcox, S.B., 2005. Human Factors Roundtable. Designing usability into medical products. Boca Raton, FL: CRC Press, 31-54.

Wilcox, S.B., 2005. Finding and Using Data Regarding the Shape and Size of the User's Body. In: M.E. Wiklund and S.B. Wilcox, eds, Designing Usability into Medical Products. Boca Raton, FL: CRC Press, 77-83.

Williams, G.L., 2007. Improving fit through the integration of anthropometric data into a computer aided design and manufacture based design process. Thesis (PhD). Loughborough University.

Winters, J., 2008. MRI and the Physical Agents (EMF) Directive. King's College London: The Institute of Physics. 